\title{
PELANGGAN PERGUDANGAN ARCADIA BLOK G20 MERENCANAKANPEMBANGUNAN JARINGAN DISTRIBUSI BARU
}

\author{
Novi Gusti Pahiyanti ${ }^{11}$, Erlina $^{2)}$,Akhbar Nazzari Ramdhart ${ }^{3)}$ \\ Teknik Elektro, Sekolah Tinggi Teknik - PLN \\ 1nove140304@gmail.com, \\ 2erlina_st@yahoo.com
}

\begin{abstract}
Development economy in the district of Tangerang increased significantly, especially in the areas of industrial. This pushes the level of demand for electrical energy is growing. To meet these needs, it is necessary to mobilize the distribution of electricity to customers as well as possible. In this regard, it takes the addition of new distribution systems in blocks that have not been connected to the distribution network of customers. Before you realize it must be done before the planning process to consider several aspects of the construction, operation, and maintenance of the system. There are some indications that influence the course and outcome of planning such as customer load calculation, load characteristics, network pattern, as well as the voltage drop distribution substation site selection, to obtain a satisfactory planning. Great power to be distributed to every warehouse or factory in Warehousing Arcadia Block G20 is 2.200 VA, 33.000 VA and 66.000 VA with equitable division. The planning process is influenced by the circumstances in carrying out development in accordance with the target of a predetermined time.
\end{abstract}

Keywords: Network Distribution, Voltage Drop, Long Conductor .

Abstrak : Perkembangan perekonomian di daerah Tangerang meningkat signifikan, terutama di bidang industri. Hal ini mendorong tingkat permintaan energi listrik semakin bertambah. Guna memenuhi kebutuhan tersebut, maka perlu diselenggarakan penyaluran tenaga listrik kepada pelanggan dengan sebaik mungkin. Berkaitan dengan hal tersebut, maka dibutuhkan penambahan sistem distribusi baru di blok-blok yang belum terpasang jaringan distribusi ke pelanggan. Sebelum merealisasikannya harus dilakukan dulu proses perencanaan dengan mempertimbangkan beberapa aspek dalam pembangunan, pengoperasian, dan pemeliharaan sistem. Ada beberapa indikasi yang mempengaruhi jalannya dan hasil perencanaan seperti perhitungan beban pelanggan, karakteristik beban, pola jaringan, jatuh tegangan serta pemilihan lokasi gardu distribusi, sehingga dapat diperoleh perencanaan yang memuaskan. Besar daya yang akan disalurkan pada setiap gudang atau pabrik di Pergudangan Arcadia Blok G20 adalah 2.200 VA, 33.000 VA dan 66.000 VA dengan pembagian merata. Proses perencanaan ini dipengaruhi oleh situasi dan kondisi dalam melaksanakan pembangunan sesuai dengan target waktu yang ditentukan sebelumnya.

Kata Kunci :Jaringan Distribusi, Jatuh Tegangan, Panjang Saluran

\section{PENDAHULUAN}

Di era globalisasi ini tingkat partumbuhan pembangunan menjadi salah satu faktor yang mempengaruhi kemajuan suatu negara. Di Indonesia tingkat kemajuan pertumbuhan pembangunan meningkat sangat signifikan. Terutama dalam bidang ketenagalistrikan. Penyedia- an tenaga listrik di Indonesia saat ini baru mencapai elektrifitas sekitar $90 \%$.

Pertambahan permintaan energi listrik yang terus meningkat menimbulkan jumlah energi listrik yang dibutuhkan juga meningkat. Untuk mengatasi keadaan tersebut, maka perlu dilakukan peningkatan kapasitas, keandalan, kontinuitas dan pelayanan baik di pembangkit, transmisi 
maupun jaringan distribusi. Dengan menambah kapasitas jaringan harus dilakukan pembangunan jaringan baru di lokasi lain. Hal ini dilakukan untuk mendekatkan pusat penyaluran dengan pusat beban atau pelanggan, sehingga mengurangi jatuh tegangan dan rugi-rugi daya dalam penyaluran tenaga listrik. Untuk merealisasikan tujuan yang telah diuraikan diatas, maka dibutuhkan proses perencanaan yang baik agar menghasilkan suatu sistem jaringan distribusi yang andal dan sesuai permintaan pelanggan. Perencanaan diperlukan sebab berkaitan dengan tujuan pengembangan sistem distribusi yang memenuhi beberapa kriteria teknis dan ekonomis. Perencanaan pembangunan jaringan distribusi baru haruslah dilakukan dengat sangat sistemik dengan pendekatan yang didasarkan pada prakiraan beban guna mendapatkan hasil yang optimal dan dapat menunjang selama beberapa tahun kedepan.

\section{LANDASAN TEORI}

\subsection{Sistem Distribusi}

Sistem penyaluran tenaga listrik dari pembangkit tenaga listrik ke konsumen (beban). Proses penyaluran tenaga listrik ini melalui beberapa tahap, yaitu dari pembangkit tenaga listrik penghasil energi listrik, disalurkan ke jaringan transmisi (SUTET) langsung ke gardu induk. Dari gardu induk tenaga listrik disalurkan ke jaringan distribusi primer (Tegangan Menengah), dan melalui gardu distribusi langsung ke jaringan distribusi sekunder (Tegangan Rendah), tenaga listrik dialirkan ke konsumen. Dengan demikian sistem distribusi tenaga listrik berfungsi membagikan tenaga listrik kepada pihak pemakai melalui jaringan tegangan rendah (JTR), sedangkan suatu saluran transmisi berfungsi untuk menyalurkan tenaga listrik bertegangan ekstra tinggi ke pusat-pusat beban dalam daya yang besar (melalui jaringan distribusi).

Sistem pembangkit terdiri dari satu atau lebih unit pembangkit yang akan mengkonversikan energi mekanik menjadi energi listrik dan harus mampu menghasilkan daya listrik yang cukup sesuai kebutuhan konsumen. Sistem transmisi berfungsi mennyalurkan energi listrik dari unit-unit pembangkitan di berbagai lokasi dengan jarak yang jauh ke sistem distribusi, sedangkan sistem distribusi berfungsi untuk menghantarkan energi listrik ke konsumen.

\subsection{Struktur Jaringan Distribusi}

Sistem distribusi tenaga listrik merupakan sistem yang diproses setelah sistem transmisi dan terdiri dari beberapa bagian, yaitu :

\subsubsection{Gardu Induk}

Gardu Induk berfungsi menurunkan tegangan dari jaringan transmisi dan menyalurkan tenaga listrik melalui jaringan distribusi primer.

\subsubsection{Jaringan Distribusi Primer}

Jaringan distribusi primer merupakan tahap berikutnya dari jaringan transmisi dalam upaya menyalurkan tenaga listrik ke konsumen. Jaringan distribusi primer memiliki tegangan sistem sebesar $20 \mathrm{kV}$.

\subsubsection{Gardu Distribusi}

Gardu distribusi berfungsi merubah tegangan listrik dari jaringan distribusi primer menjadi tegangan konsumen. Kapasitas transformator yang digunakan pada Gardu Pembagi ini tergantung pada jumlah beban yang akan dilayani dan luas daerah pelayanan beban.

\subsubsection{Jaringan Distribusi Sekunder}

Jaringan distribusi sekunder merupakan jaringan tenaga listrik yang langsung berhubungan dengan konsumen. Besarnya tegangan untuk jaringan distribusi sekunder in 230/400 V. Tegangan $230 \mathrm{~V}$ merupakan tegangan antara fasa dengan netral, sedangkan tegangan $400 \mathrm{~V}$ merupakan tegangan fasa dengan fasa.

\subsection{Gardu Distribusi}

Gardu distribusi adalah suatu bangunan gardu listrik yang dipasok dengan tegangan $20 \mathrm{kV}$ dari Saluran Kabel Tegangan Menengah (SKTM) atau Saluran Udara Tegangan Menengah (SUTM). Gardu distribusi ini terdiri dari instalasi Perlengkapan Hubung Bagi Tegangan Menengah (PHB-TM), Transformator Distribusi (TD), dan 
Perlengkapan Hubung Bagi Tegangan Rendah (PHB-TR) untuk memasok kebutuhan tenaga listrik bagi para pelanggan baik dengan Tegangan Menengah (TM $20 \mathrm{kV}$ ) maupun Tegangan Rendah (TR 220/380 V). Konstruksi gardu distribusi dirancang berdasarkan optimalisasi biaya terhadap maksud dan tujuan penggunaannya yang kadang kala harus disesuaikan dengan peraturan Pemerintah Daerah setempat.

Pembangunan gardu distribusi terdiri dari gardu pasangan luar dimana semua instalasi listriknya kedap air (Gardu Portal dan Gardu Cantol) dan gardu pasangan dalam dimana instalasinya tidak kedap air (Gardu Beton dan Gardu Kios). Berdasarkan klasifikasi penggunaannya gardu distribusi dapat dibagi menjadi :

1) Gardu pelanggan umum (daya $<200$ kVA) dengan kapasitas transformator distribusi yang terpasang $50 \mathrm{kVA}$ s/d 1000 kVA.

2) Gardu pelanggan khusus (daya $>200$ kVA) dengan berlangganan TM/TM/TM (TM murni) yang dilengkapi dengan transformator distribusi.

Selain gardu distribusi, PLN menggunakan gardu hubung sebagai sarana untuk mengatur pasokan listrik. Gardu hubung adalah gardu yang ditujukan untuk memudahkan manuver pembebanan dari satu penyulang ke penyulang lain yang dapat dilengkapi RTU (Remote Terminal Unit). Untuk fasilitas ini disarankan untuk dilengkapi dengan fasilitas DC Supply dari Trafo Distribusi pemakaian sendiri atau Trafo Distribusi untuk umum yang diletakkan dalam satu kesatuan.

\subsection{Jenis -Jenis Gardu Portal 2.4.1. Gardu Portal}

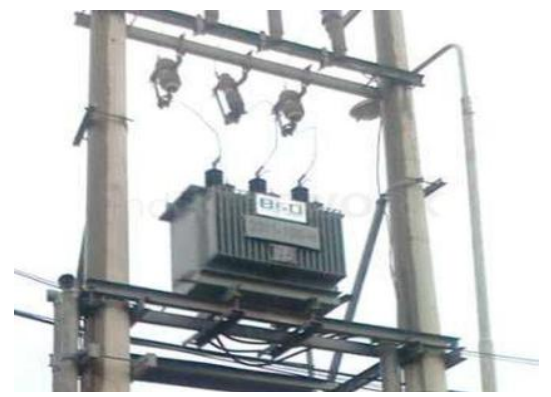

Gambar 2.1 Gardu Portal
Umumnya konfigurasi Gardu Portal adalah $\mathbf{T}$ section dengan peralatan pengaman FCO (Fuse Cut Out) sebagai pengaman hubung singkat transformator dengan elemen pelebur (fuse link type expulsion) dan Lightning Arrester sebagai sarana pencegah naiknya tegangan pada transformator akibat surja petir.

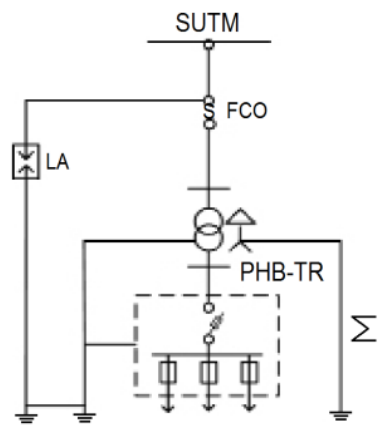

Gambar 2.2. Diagram Satu Garis Gardu Portal

Untuk Gardu Tiang pada sistem jaringan lingkaran terbuka (open-loop), seperti pada sistem distribusi dengan saluran kabel bawah tanah, konfigurasi peralatan adalah $\pi$ section dimana trafo distribusi dapat di catu dari arah berbeda yaitu posisi Incoming - Outgoing atau dapat sebaliknya.

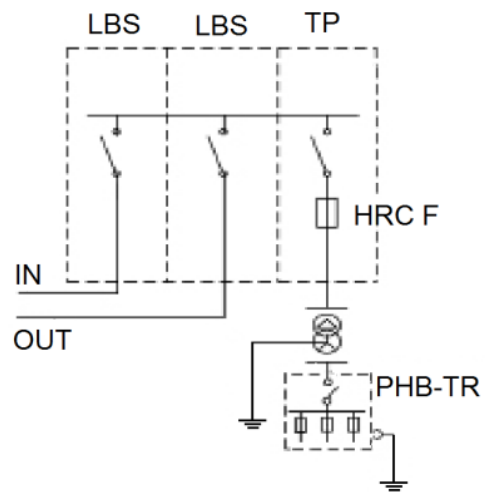

Gambar 2.3. Diagram Satu Garis Portal Konfiguarsi IT Secon

Guna mengatasi faktor keterbatasan ruang pada Gardu Portal, maka digunakan konfigurasi switching atau proteksi yang sudah terakit ringkas sebagai RMU (Ring Main Unit). Peralatan Switching IncomingOutgoing berupa Pemutus Beban atau LBS (Load Break Switch) atau Pemutus Beban Otomatis (PBO) atau CB (Circuit Breaker) yang bekerja secara manual (atau digerakkan dengan remote control). 


\section{METODE PENELITIAN}

Pengambilan data dilakukan pada daerah pergudangan Arcadia Blok G 20 sebagai data pengamatan yang akan di cari.

\subsection{Penentuan Denah Lokasi \\ Pergudangan Arcadia Blok G20}

Berikut ini merupakan gambar denah lokasi Pergudangan Arcadia Blok G20 secara keseluruhan, yaitu :

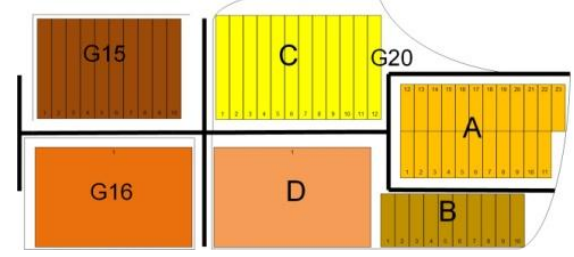

Gambar 3.1. Denah Lokasi Kondisi Pergudangan Arcadia Blok G20

\subsection{Prakiraan Beban Penyulang Pada Trafo Gardu Induk Cengkareng}

Prakiraan beban merupakan kunci utama untuk mengetahui berapa jumlah beban yang terpakai dan beban yang masih tersedia. Hal ini mendukung untuk proses perencanaan masa depan. Berikut ini merupakan tabel prakiraan beban dari Gardu Induk Cengkareng.

Tabel 3.1. Prakiraan Beban Penyulang dan Trafo GI Cengkareng Dengan PB Kolektif Calon Pelanggan

\begin{tabular}{|c|c|c|c|c|c|}
\hline \multirow[t]{2}{*}{$\begin{array}{c}\text { Penyulang/ } \\
\text { Trafo }\end{array}$} & \multicolumn{2}{|c|}{ Saat Ini } & \multirow{2}{*}{$\begin{array}{r}\text { PB } \\
\text { A }\end{array}$} & \multicolumn{2}{|c|}{$\begin{array}{l}\text { Beban } \\
\text { Akan } \\
\text { Datang }\end{array}$} \\
\hline & $\mathbf{A}$ & $\%$ & & $\mathbf{A}$ & $\%$ \\
\hline P. Lipstik & 300 & 70 & $\begin{array}{c}11,5 \\
5\end{array}$ & $\begin{array}{c}311, \\
55\end{array}$ & 75 \\
\hline $\begin{array}{c}\text { Trafo } 5 \\
\text { Gl } \\
\text { Cengkareng }\end{array}$ & $\begin{array}{l}1.7 \\
32\end{array}$ & 86 & $\begin{array}{c}11,5 \\
5\end{array}$ & $\begin{array}{l}1.74 \\
3,55\end{array}$ & 87 \\
\hline
\end{tabular}

\subsection{Permintaan Beban Pergudangan Arcadia Blok G20}

Sebelum melakukan perencanaan, perlu diketahui berapa banyak beban yang akan didistribusikan ke pelanggan. Hal ini dapat ditinjau dari berapa jumlah pelanggan yang akan dipasang jarinigan listrik dan berapa besar beban yang dibutuhkan.

Berikut ini merupakan data jumlah permintaan beban Pergudangan Arcadia
Blok 20, dengan beban sebesar 2.200 VA, 33.000 VA dan 66.000 VA per-unit gudang. Dimana data ini merupakan data beban awal pelanggan yang disediakan oleh pihak pengembang.

Tabel 3.2. Jumlah Permintaan Beban Pergudangan Arcadia Blok G20

\begin{tabular}{|c|c|c|c|c|}
\hline No. & Blok & Komplek & $\begin{array}{c}\text { Jumlah } \\
\text { Unit }\end{array}$ & $\begin{array}{c}\text { Permintaan } \\
\text { Beban (VA) }\end{array}$ \\
\hline 1 & G15 & & 10 & 83.600 \\
\hline 2 & G16 & & 1 & 66.000 \\
\hline \multirow{3}{*}{3} & \multirow{3}{*}{ G20 } & $\mathrm{A}$ & 23 & 173.800 \\
\cline { 3 - 5 } & & $\mathrm{B}$ & 10 & 83.600 \\
\cline { 3 - 5 } & & $\mathrm{C}$ & 12 & 118.800 \\
\cline { 3 - 5 } & & $\mathrm{D}$ & 1 & 66.000 \\
\hline \multicolumn{2}{|l|}{ JUMLAH } & & 57 & 591.800 \\
\hline
\end{tabular}

Blok G15 dan Blok G16 sudah teraliri listrik yang disuplai oleh gardu BTC29 dengan kapasitas transformator yang dimutasi (direncanakan) dari 160 kVA menjadi $400 \mathrm{kVA}$.

\subsection{Tahap Survey Dan Tracking}

Sebelum melakukan perencanaan, hal pertama yang dilakukan adalah melakukan survei lapangan. Dalam tahap survei ini, ada beberapa hal yang harus dilakukan untuk mendapatkan data yang optimal, antara lain:

1. Survei lokasi, untuk mengetahui keadaan lokasi. Hal ini penting untuk mengetahui karakteristik jaringan sekitarnya.

2. Wawancara, untuk mendapatkan gambaran awal dalam perencanaan jalur jaringan. Hal ini dapat kita peroleh dari penduduk setempat atau pihak yang bertanggung jawab di bidangnya.

Data yang diperoleh ini akan dijadikan pertimbangan untuk survei lanjutan. Pada survei lanjutan ini didapatkan data sebagai berikut :

1) Data tracking GPS

2) Hasil pengukuran parameter jarak menggunakan Distance Meter

3) Gambar perencanaan jalur jaringan

4) Gambar kondisi daerah

5) Gambar lokasi pemasangan tiang dan gardu 
Data utama pada perencanaan jaringan distribusi ini adalah gambar dan hasil pengukuran. Gambar ini diperoleh dari proses perencanaan secara manual yang disesuaikan dengan keadaan di lapangan.

Tracking merupakan penyusuran daerah jalur jaringan dari awal sampai ujung jaringan. Tujuannya adalah untuk menyesuaikan lokasi antara di GPS dengan keadaan aslinya. Di PT. PLN (Persero) Komplek Cengkareng menggunakan aplikasi Geo Tracker yang diinstal di perangkat Android sebagai pengganti GPS. Dimana pada aplikasi Geo Tracker ini dapat membuka peta yang sudah dimodifikasi, peta yang sudah dilengkapi peta jaringan dan lokasi gardu untuk wilayah kerja Komplek Cengkareng.

\subsection{Tahap Perencanaan}

Dalam tahap perencanaan, sebaiknya membuat diagram perencanaan agar dapat berjalan sesuai apa yang diinginkan.

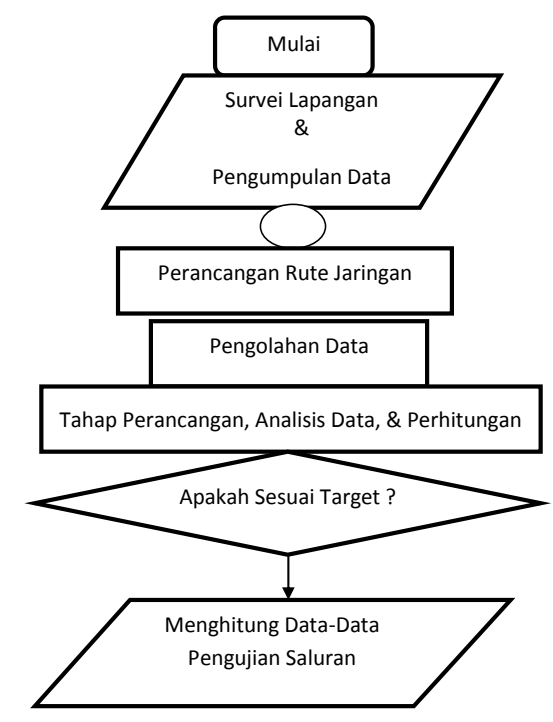

Gambar 3.2. Diagram Perencanaan

\subsection{Menentukan Konstruksi Jaringan JTR}

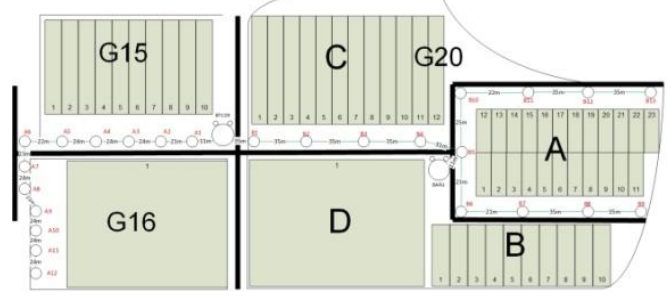

Gambar 3.3. Denah Lokasi Letak Tiang JTR
Konstruksi tiang jaringan listrik memiliki berbagai macam jenis sesuai dengan fungsi dan penggunaannya. Konstruksi tiang biasanya ditentukan berdasarkan lokasi titik tiang.

Pada perencanaan jaringan distribusi di Pergudangan Arcadia Blok G20, jenis tiang yang digunakan adalah :

a) Tiang A12, B6, dan B10 menggunakan konstruksi tiang tipe TR-3 yang merupakan tiang akhir dengan konstruksi beton memiliki ketinggian 9 meter, kekuatan tiang 350 daN, menggunakan fixed deadend clamp yang dilengkapi dengan plastic strap.

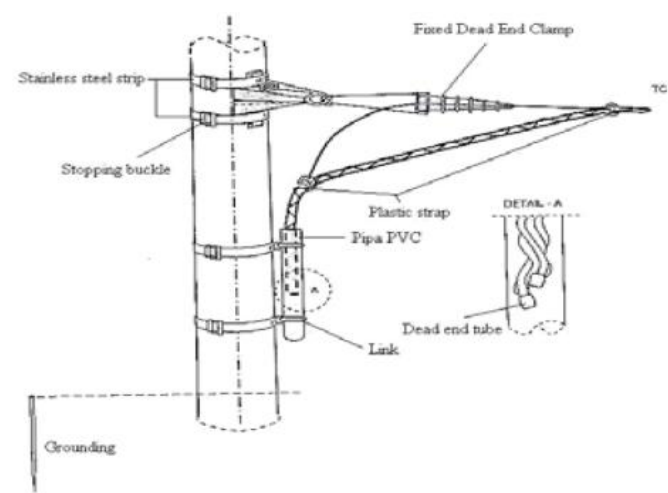

Gambar 3.4. Kontruksi Tiang Tipe TR-3

b) Tiang B5 menggunakan konstruksi tiang tipe TR-4 yang merupakan tiang penyangga pada persimpangan, memiliki tiang dengan ketinggian 9 daN dan kekuatan tiang 350 daN. Kedua saluran yang saling bersilangan dikaitkan pada suspension small angle assembly.

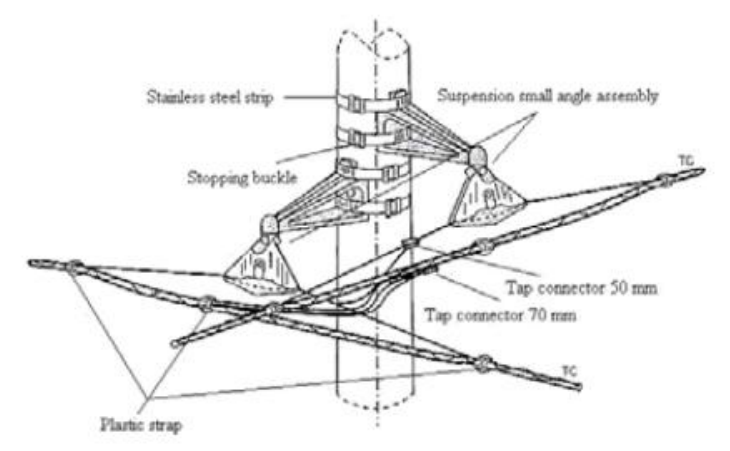

Gambar 3.5. Konstruksi Tiang Tipe TR-4

c) Tiang A6, A8, A9, B6 dan B10 menggunakan konstruksi tiang tipe TR-2 yang merupakan tiang sudut 
rang dari $45^{\circ}$ dengan menggunakan large angle assembly (penggantung untuk tiang sudut atau belokan).

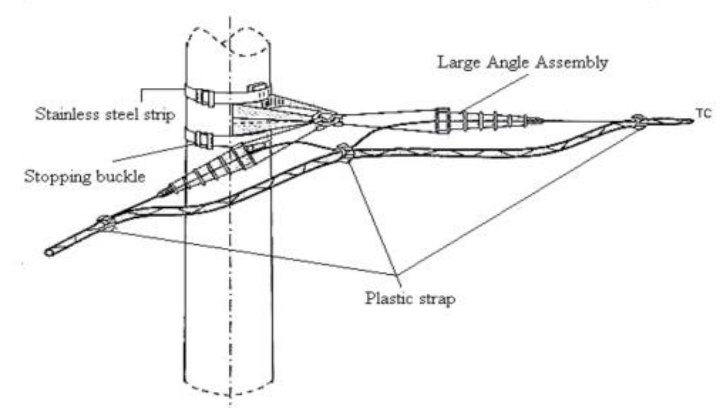

Gambar 3.6. Kontruksi Tiang Tipe TR-2

d) Tiang A1, A2, A3, A4, A5, A7, A10, A11, B1, B2, B3, B4, B7, B8, B11 dan B12 menggunakan konstruksi tiang tipe TR-1 yang merupakan tiang penyangga yang dilengkapi dengan suspension small angle assembly (penggantung untuk tiang tumpu atau penyangga), dengan tinggi tiang 9 meter dan kekuatan tiang 200 daN.

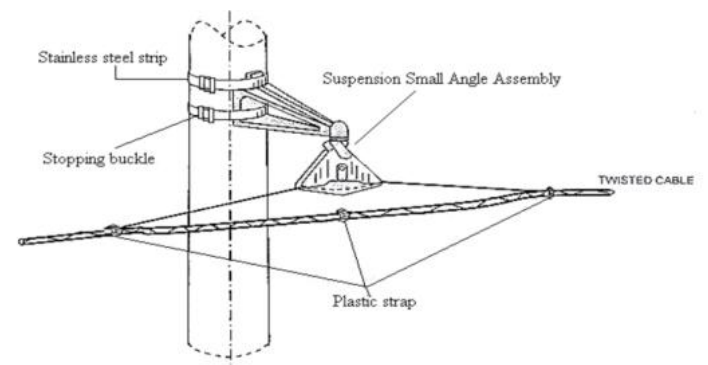

Gambar 3.7. Konstruksi Tiang Tipe TR 1

\subsection{Pemilihan Penghantar Saluran}

Hal yang paling diperhatikan dalam pemilihan penghantar adalah kondisi beban di lapangan, apabila beban sudah overload dan penghantar sudah tidak memungkinkan untuk digunakan, maka penghantar harus diganti dengan luas penampang yang lebih besar. Karena semakin besar luas penampang, maka semakin besar pula beban yang dapat disalurkan.

Berhubungan dengan pembahasan di atas, untuk memperoleh pendistribusian yang optimal, maka kabel lama dari SKTM Penyulang Lipstik hingga Gardu yang akan dibangun harus diganti dengan kabel yang memiliki luas penampang lebih besar. Kabel yang digunakan adalah kabel power NA2XSEYBY $3 \times 240 \mathrm{~mm}^{2}$.
Untuk JTR yang akan dipasang di Pergudangan Arcadia Blok G20, digunakan kabel pilin Alumunium jenis NFA2X-T dengan ukuran $70 \mathrm{~mm}^{2}$. Sedangkan untuk SR digunakan kabel jenis NFA2X $2 \times 10 \mathrm{~mm}^{2}$.

\subsection{Penentuan Lokasi Gardu}

Dalam penentuan lokasi gardu, perencanaan harus memperhatikan beberapa hal, yaitu :

1) Total Beban, letak trafo harus bisa memenuhi total beban yang ada, sehingga lokasi trafo harus dapat mencakup seluruh lokasi beban.

2) Persebaran Beban, lokasi trafo harus berada di ujung awal tarikan JTR. Selanjutnya, penentuan lokasi trafo ini juga harus mempertimbangkan penambahan beban baru atau perluasan jaringan.

3) Lokasi Tiang Akhir, maksimal jarak tarikan tiang JTR dari trafo adalah 350 meter dengan jarak rata-rata maksimum 35 meter per-gawang.

Di Pergudangan Arcadia Blok G20, gardu distribusi dibangun di lahan sarana pertama. Hal ini bertujuan agar proses persebaran beban merata dan jarak gawang antar tiang tidak terlalu jauh. Sehingga diharapkan rugi-rugi daya dan jatuh tegangan pada jaringan tidak terlalu besar.

\section{HASIL DAN PEMBAHASAN}

\subsection{Perhitungan Perencanaan Jaringan Distribusi Yang Akan Dibangun}

Pada Proses perencanaan jaringan distribusi yang akan dibangun berlokasi di Pergudangan Arcadia Blok G20, Jalan Daan Mogot Km. 21, Batu Ceper, Tangerang, Banten. Dengan luas lahan $69.204 \mathrm{~m}^{2}$ yang terdiri dari blok $\mathrm{G} 15$ $11.505 \mathrm{~m}^{2}$ terdapat 10 unit gudang yang sudah dibangun, $19.733 \mathrm{~m}^{2}$ blok G16 terdapat 1 unit gudang dan pabrik yang sudah dibangun. Dan blok $2037.965 \mathrm{~m}^{2}$ komplek A terdapat 23 unit gudang yang sudah bangun, komplek B terdapat 10 unit gudang yang akan dibangun, komplek $\mathrm{C}$ terdapat 12 unit gudang yang akan dibangun dan komplek $D$ terdapat 1 unit gudang dan pabrik yang akan dibangun. 


\subsection{Perhitungan Jatuh Tegangan}

Untuk mendukung proses perencanaan, maka perlu dihitung berapa besar jatuh tegangan pada jaringan tersebut. Hal ini dilakukan untuk menghindari rugi-rugi daya dan jatuh tegangan ketika sudah dilaksanakan pembangunan gardu dan jaringan distribusi di Pergudangan Arcadia Blok G20.

Dengan asumsi besarnya jatuh tegangan $+5 \%$ dan $-10 \%$ dari tegangan operasinya berdasarkan Standar PLN No.1 tahun 1985, jarak terjauh dari gardu ke tiang ujung JTR adalah 350 meter, dan sambungan pelayanan menggunakan Tipe A yaitu dengan menarik langsung kabel dari JTR ke APP pelanggan. Perhitungan jatuh tegangan ini dilakukan pada sisi JTR dengan menggunakan parameter jarak gawang tiang JTR dan luas penampang JTR.

\subsection{Menghitung Arus Beban}

Besarnya nilai jatuh tegangan dapat dihitung dengan beberapa parameter, yaitu :

1. Di Blok G15 ada 10 unit gudang

Beban $(S)=2.200 \mathrm{VA} \times 8$ unit $=17.600 \mathrm{VA}$

Beban $(S)=33.000 \mathrm{VA} \times 2$ unit $=66.000 \mathrm{VA}$

Total Beban $(S)=17.600 \mathrm{VA}+$ $66.000 \mathrm{VA}=83.600 \mathrm{VA}$

Dengan asumsi $\cos \varphi=0,8$ dan $\sin \varphi=0,6$

Jika $S=\sqrt{3} I V$, maka Arus Beban $(I)=\frac{S}{\sqrt{3} V}=\frac{83.600 \mathrm{VA}}{\sqrt{3} \times 400 \mathrm{~V}}=120,6$ Ampere

2. Di Blok G16 ada 1 unit pabrik

Total Beban G16 $(S)=66.000 \mathrm{VA} \times 1$ unit $=66.000 \mathrm{VA}$

Dengan asumsi $\cos \varphi=0,8$ dan $\sin \varphi=0,6$

Jika $S=\sqrt{3} I V$, maka Arus Beban $(I)=\frac{S}{\sqrt{3} V}=\frac{66.000 \mathrm{VA}}{\sqrt{3} \times 400 \mathrm{~V}}=95,2$ Ampere

3. Di Blok G20 terdapat 46 unit gudang

a) Komplek $A$ ada 23 unit gudang

Beban $(S)=2.200 \mathrm{VA} \times 19$ unit $=41.800 \mathrm{VA}$

Beban $(S)=33.000 V A \times 4$ unit $=132.000 \mathrm{VA}$

Total Beban $(S)=41.800 \mathrm{VA}+$ $132.000 \mathrm{VA}=173.800 \mathrm{VA}$
Dengan asumsi $\cos \varphi=0,8$ dan $\sin \varphi=0,6$

Jika $S=\sqrt{3} I V$, maka Arus

Beban $\quad(I)=\frac{S}{\sqrt{3} V}=\frac{173.800 \mathrm{VA}}{\sqrt{3} \times 400 \mathrm{~V}}=$

250,8 Ampere

b) Komplek $B$ ada 10 unit gudang

Beban $(S)=2.200 \mathrm{VA} \times 8$ unit $=17.600 \mathrm{VA}$

Beban $(S)=33.000 \mathrm{VA} \times 2$ unit

$=66.000 \mathrm{VA}$

Total Beban $(S)=17.600 \mathrm{VA}+$ $66.000 \mathrm{VA}=83.600 \mathrm{VA}$

Dengan asumsi $\cos \varphi=0,8$ dan $\sin \varphi=0,6$

Jika $S=\sqrt{3} I V$, maka Arus

Beban $\quad(I)=\frac{S}{\sqrt{3} V}=\frac{83.600 \mathrm{VA}}{\sqrt{3} \times 400 \mathrm{~V}}=$

120,6 Ampere

C) Komplek $\mathrm{C}$ ada 12 unit gudang

Beban $(S)=2.200 V A \times 9$ unit $=19.800 \mathrm{VA}$

Beban $(S)=33.000 \mathrm{VA} \times 3$ unit $=99.000 \mathrm{VA}$

Total Beban $(S)=19.800 \mathrm{VA}+$ $105.000 \mathrm{VA}=118.800 \mathrm{VA}$

Dengan asumsi $\cos \varphi=0,8$ dan $\sin \varphi=0,6$

Jika $S=\sqrt{3} I V$, maka Arus Beban $\quad(I)=\frac{S}{\sqrt{3} V}=\frac{118.800 \mathrm{VA}}{\sqrt{3} \times 400 \mathrm{~V}}=$ 171,4 Ampere

d) Komplek $D$ ada 1 unit pabrik

Beban $(S)=66.000 \mathrm{VA} \times 1$ unit $=66.000 \mathrm{VA}$

Dengan asumsi $\cos \varphi=0,8$ dan $\sin \varphi=0,6$

Jika $S=\sqrt{3} I V$, maka Arus Beban $\quad(I)=\frac{S}{\sqrt{3} V}=\frac{66.000 \mathrm{VA}}{\sqrt{3} \times 400 \mathrm{~V}}=$ 95,2 Ampere

\subsection{Menentukan Kapasitas Trafo}

Untuk menentukan kapasitas trafodistribusi, ada beberapa hal yang harus dipertimbangkan, yaitu faktor beban, faktor diversitas dan faktor kebutuhan beban

Karakteristik beban pergudangan pada umumnya berupa peralatan listrik yang dapat menopang kehidupan seharihari, seperti lampu penerangan, televisi, mesin, pompa air dan lain-lain. Beban pergudangan memiliki besar faktor kebersamaan beban sebesar 70-100\%, 
faktor diversitas 1,2-1,3 dan faktor beban $10-15 \%$.

Jumlah total beban blok G15, blok G16 dan blok G20 adalah 591.800 VA. Dengan memperhitungkan gardu BTC29 dengan daya $160 \mathrm{kVA}$ yang akan dimutasi menjadi daya 400 kVA yang sudah mensuplai daya ke blok G15, blok G16, blok G20 komplek C dan D. Jumlah bebannya menjadi 334.400 VA. Semua blok diasumsikan memiliki faktor kebersamaan beban $80 \%$ atau 0,8., maka dapat dihitung beban puncak sebagai berikut :

Beban Puncak $\left(P_{\text {max }}\right)=$

$0,8 \times 334.400 \mathrm{VA}=267.520 \mathrm{VA}$ untuk trafo BTC29

Beban Puncak $\left(P_{\max }\right)=$

$0,8 \times 257.400 \mathrm{VA}=205.920 \mathrm{VA}$ untuk trafo yang direncanakan.

Daya trafo terpasang harus lebih besar dari pada daya yang terpasang PLN, supaya trafo tidak bekerja secara maksimum. Faktor pembebanan trafo sebaiknya $80 \%$ dari pembebanan agar bekerja efektif.

\section{KESIMPULAN}

1. Berdasarkan kebutuhan, kapasitas transformator yang digunakan adalah 400 kVA, panjang saluran udara tegangan rendah (SUTR) terjauh adalah 350 meter, dan jenis penghantar JTR Alumunium berdiameter $70 \mathrm{~mm}^{2}$.

2. Dari proses perhitungan diperoleh tegangan gardu distribusi ke tiang ujung JTR adalah Blok G15 16,959 Volt (4,239\%), Blok G16 13,387 Volt (3, 346\%), Blok G20 Komplek A 35,27 Volt $(8,817 \%)$, Blok G20 Komplek B 16,959 Volt $(4,239 \%)$, Blok G20 Komplek C 24,103 Volt $(6,025 \%)$, Blok G20 Komplek D 13,387 Volt (3,346\%)atau masih dibawah $10 \%$ dari tegangan operasinya. $\mathrm{Hal}$ ini berjalan baik sesuai standar PLN.

\section{REFERENSI}

1. Kadir, Abdul (2006). Distribusi dan Utilitas Tenaga Listrik, Jakarta : UI Press

2. Kelompok Kerja Standar Konstruksi Distribusi Jaringan Tenagan Listrik (2010). Standar Konstruksi Gardu Distribusi dan Gardu Hubung Tenaga Listrik. Jakarta : PT. PLN (Persero)

3. Kelompok Kerja Standar Konstruksi Distribusi Jaringan Tenagan Listrik (2010). Standar Konstruksi Jaringan Distribusi Tenaga Listrik Tegangan Rendah. Jakarta : PT. PLN (Persero)

4. Marsudi, Djiteng (2016). Operasi Sistem Tenaga Listrikk, Jakarta : UI Press

5. Nugroho, Febrian (2014),

Perencanaan Pembangunan Jaringan

Dristribusi Listrik Pedesaan

Kabupaten Wonogiri. Makalah

Seminar Kerja Praktek. Universitas Diponegoro, Semarang.

6. Panitia Revisi PUIL - Persyaratan Umum Instalasi Listrik 2000 (PUIL 2000) SNI 04-0225-2000 - Yayasan PUIL Jakarta, 2000

7. Sarimun, Wahyudi (2011). Buku Saku Pelayanan Teknik YANTEK (Edisi Kedua). Jakarta : Garamond.

8. Suswanto, Daman (2009). Sistem Distribusi Tenaga Listrik. Padang : Universitas Negeri Padang.

9. SPLN 1 (1995). Tegangan-Tegangan Standar. Jakarta : Departemen Pertambangan dan Energi. 